International Journal of Advanced Chemistry, 8(2)(2020) 203-208
International Journal of Advanced Chemistry
SPC
Website: $w w w . s c i e n c e p u b c o . c o m / i n d e x . p h p / I J A C$
Research paper

\title{
Development and validation of valganciclovir hydrochloride in bulk and pharmaceutical dosage form by HPTLC method
}

\author{
Karthik K. 1 *, Jose Gnana Babu C ${ }^{1}$, Sowmya H. G. ${ }^{1}$ \\ ${ }^{1}$ Department of Pharmaceutical analysis, Bharathi College of Pharmacy, Bharathinagara, KM \\ Doddi, Maddur Taluk, Mandya district-571422 \\ *Corresponding author E-mail: Karthik11201243@gmail.com
}

\begin{abstract}
A simple, rapid and accurate High performance thin layer chromatography is described for the Development and validation of HPTLC method for Valganciclovir Hydrochloride in bulk and Pharmaceutical dosage form. The separation is carried out on Merck TLC aluminum sheets of silica gel 60 F254 using Chloroform: Methanol: Ammonia (6.5:3.4:0.1v/v) mobile phase. Quantification was done by Densitometric scanning at $254 \mathrm{~nm}$. The linearity was found to be the range of $100-500 \mathrm{ng} / \mathrm{spot}$ for Valganciclovir hydrochloride with the correlation coefficient of 0.9993 . The regression equation was found to be $\mathrm{Y}=10.168 \mathrm{x}-94.8$. The $\mathrm{Rf}$ value of Valganciclovir hydrochloride was found to be 0.74 . The LOD and LOQ were found to 9.19 and 27.87 respectively. Average recovery was found to be $99.66 \%$ which show that the method was free from interference from excipients present in the formulation. Simultaneously the Percentage relative standard deviation was well within the range of $2 \%$. The above method was validated according to the ICH guidelines. The established method enabled accurate, precise and applied to the analysis of Valganciclovir hydrochloride in bulk and Pharmaceutical dosage form.
\end{abstract}

Keywords: Valganciclovir Hydrochloride; HPTLC; Validation; ICH; Tablet Dosage Form.

\section{Introduction}

Valganciclovir hydrochloride is a hydrochloride salt form of Valganciclovir, a prodrug form of ganciclovir, a nucleoside analogue of 2'deoxyguanosine, with antiviral activity. The completion of phosphorylation, Valganciclovir is incorporated into DNA, resulting in the inhibition of viral DNA polymerase, and viral replication. Valganciclovir hydrochloride is an antiviral agent that is used to treat cytomegalovirus retinitis in patients with AIDS, and for the prevention of cytomegalovirus infections in organ transplant recipients who have received an organ from a CMV-positive donor The Valganciclovir acts by slowing the growth of the CMV virus. It helps prevent the spread of infection to other areas of the body. ${ }^{[2]}$<smiles>CC(C)[C@H](N)C(=O)OCC(CO)OCn1cnc2c(=O)[nH]c(N)nc21</smiles>

Fig. 1: Chemical Structure of Valganciclovir Hydrochloride.

Valganciclovir hydrochloride contains not less than $97 \%$ and not more than $102 \%$. Hydrochloride is calculated based on the anhydrous and solvent free basis. Valganciclovir hydrochloride is available in the form of White to off crystalline powder. The crystals from water+isopropranol undergo phase changes at $142^{\circ} \mathrm{C}$. It is freely soluble in Water, Dimethyl sulfoxide, Methanol, Acetonitrile and Acetic acid. Valganciclovir hydrochloride is available under the brand name of Valcyte, Cymeral, Rovalcyte and Darilin. ${ }^{[3-6]}$.

Literature Survey revealed that the drug has been estimated by UV-Spectrophotomtric ${ }^{[11-13]}$, RP-HPLC ${ }^{[14-17]}$, HPTLC ${ }^{[18]}$ and Liquid chromatographic method ${ }^{[19-21]}$ has been reported so far.

The present study describes a simple, precise and accurate analytical method for the estimation of Valganciclovir hydrochloride in bulk and pharmaceutical dosage forms. The above method was developed and validated according to the ICH guidelines. 


\section{Experimental}

\subsection{Chemicals}

The Valganciclovir hydrochloride was obtained as a gift sample from the pharmaceutical industry. All the chemicals used were of under analytical grade. The tablet formulation was procured from local pharmacy store. All dilutions were performed in standard volumetric flasks. Chloroform, Methanol, Ammonia were obtained Bharthi College of pharmacy, Bharathinagara, KM Doddi, Maddur Taluk, Mandya District, India.

\subsection{Instrumentation}

The samples were spotted in the form of bands of $6 \mathrm{~mm}$ width with a Camag microliter syringe $(100 / \mu \mathrm{l})$ on pre-coated silica gel aluminum plates $60 \mathrm{~F}-254(10 \mathrm{~cm} \times 10 \mathrm{~cm}$ with $250 \mathrm{~mm}$ thickness, E. Merck, Wilmington, USA) using a Camag Linomat-5 applicator. The plates were pre-washed with methanol and activated at $100^{\circ} \mathrm{C}$ for $5 \mathrm{~min}$ prior to chromatography. The slit dimension was kept at $6.00 \mathrm{~mm} \times 0.45$ $\mathrm{mm}$ (micro) and $20 \mathrm{~mm} / \mathrm{s}$ scanning speed was employed. The mobile phase consisted of Chloroform: Methan01: Ammonia (6.5:3.4:0.1v/v) and $10 \mathrm{ml}$ of mobile phase was used. Linear ascending development was carried out in a $10 \mathrm{~cm} \times 10 \mathrm{~cm}$ twin trough glass chamber (Camag, Switzerland) saturated with the mobile phase. The chamber saturation time for the mobile phase was 25 min at room temperature $\left(25^{\circ} \mathrm{C} \pm\right.$ 2). The length of the chromatogram run was around $8 \mathrm{~cm}$. Then the thin layer chromatography plates were dried in a current of air with the help of an air dryer. Densitometric scanning was done on a Camag TLC scanner 3 and which was operated by winCATS software.

\subsection{Stock and working standard solution}

Valganciclovir hydrochloride $(100 \mathrm{mg}$ ) was accurately weighed into a $100 \mathrm{~mL}$ volumetric flask and dissolved in a minimum volume of methanol and diluted to the required volume with methanol to furnish a solution of concentration $1000 \mathrm{ng} / \mu \mathrm{L}$. This was used as stock solution. Calibration standards were prepared over the concentration range 100-500ng/band for Valganciclovir hydrochloride by appropriate dilutions of the above-mentioned standard stock solution in a $10 \mathrm{~mL}$ volumetric flask with methanol.

\subsection{Calibration curve}

Separate stock standard solutions of Valganciclovir hydrochloride were used for the preparation of calibration standard solutions. All calibration standards were prepared freshly every day and were found to be stable during the analysis time. The plate was developed, dried and scanned as described above. After densitometric scanning, the peak area was recorded for each concentration and a calibration plot was obtained by plotting average peak area against concentration of Valganciclovir hydrochloride (ng/spot). The slope and correlation coefficient were also determined.

\subsection{Preparation of sample solution}

Brand name: VALCYTE 450mg.

Manufacturer: Roche pharmaceuticals India.

Batch number: VL 30722.

Composition: Each tablet contains 496.3mg Valganciclovir HCL and other inactive ingredients microcrystalline cellulose, povidone K-30, crospovidone and stearic acid.

The film coat applied to the tablets contains Opadry pink.

The marketed tablet formulation of VALCYTE 450mg was purchased in the local Pharmacy store. Twenty tablets of VALCYTE 450mg were accurately weighed and ground to fine powder equivalent to Valganciclovir hydrochloride (100 $\mathrm{mg})$ was accurately weighed into a $100 \mathrm{~mL}$ volumetric flask and dissolved in a minimum volume of methanol and diluted to the required volume with methanol to furnish a solution of concentration $1000 \mathrm{ng} / \mu \mathrm{L}$. This was used as stock solution.

\section{Method validation}

Validation of the above HPTLC method was carried out with respect to the following parameters:

\subsection{Precision}

Repeatability of sample application and measurement of peak area were carried out using six replicates of the same band (400ng/spot of Valganciclovir Hydrochloride). The intra-and inter-day variation for the determination of Valganciclovir Hydrochloride was carried out at three different concentration levels of 300,400 and $500 \mathrm{ng} / \mathrm{spot}$.

\subsection{Limit of detection and limit of quantification}

In order to determine the limit of detection (LOD) and limit of quantification (LOQ), Valganciclovir hydrochloride concentrations in the lower part of the linear range of the calibration curve were used. Valganciclovir hydrochloride solutions of 100-500 ng/ band were prepared and applied on the plate. The LOD and LOQ were calculated using the equation LOD $=3.3 \times \mathrm{N} / \mathrm{B}$ and LOQ $=10 \times \mathrm{N} / \mathrm{B}$, where, N is the standard deviation of the peak areas of the drugs $(n=3)$, taken as a measure of noise, and B is the slope of the corresponding calibration curve.

\subsection{Specificity}

The specificity of the method was determined by acomparing the standard drug and sample. The spot for Valganciclovir hydrochloride in the sample was confirmed by comparing the $\mathrm{R}$ values and spectra of the spot with that of the standard. The peak purity of Valganciclovir 
Hydrochloride was determined by comparing the spectra at three different levels, i.e., peak start (S), peak apex (M) and peak end (E) positions of the spot.

\subsection{Ruggedness}

Ruggedness of the method was performed by spotting 100-500ng/band of Valganciclovir Hydrochloride by three different analysts keeping the same experimental and environmental conditions.

\subsection{Accuracy}

The samples were spotted with extra 50,100 and 150\% of standard Valganciclovir Hydrochloride, and the mixture was analyzed by the proposed method. This was done to determine the recovery of the drug in the formulations.

\subsection{Robustness}

By making small \& deliberate changes in the environment and the mobile phase composition, the effects on the results were examined. The Mobile phases having different compositions of Chloroform: Methanol: Ammonia (6.5:3.4:0.1v/v) was tried and chromatograms were run. The volumes of mobile phase, temperature and relative humidity were varied in the range of $\pm 5 \%$. The plates were pre-washed by methanol and activated at $80 \pm 10^{\circ} \mathrm{C}$ for 2,5 and 7 min prior to chromatography. The spotting Time to chromatography and from chromatography to scanning was varied from 10,15 and 20 min.

\subsection{Application of the proposed method to the tablet formulation}

To determine the concentration of Valganciclovir Hydrochloride in tablets. Twenty tablets of VALCYTE 450mg were accurately weighed and ground to fine powder equivalent to $100 \mathrm{mg}$ of Valganciclovir was transferred into a 100ml volumetric flask. The standard drug from the powder was extracted using methanol. The resulting solution was filtered using a $0.45 \mu \mathrm{m}$ filter (Mill filter, Milford, MA, USA). The above solution (300ng/band) was applied on a TLC plate, followed by development and scanning, as described above.

\section{Results and discussion}

\subsection{Development of optimum mobile phase}

The TLC procedure was optimized with a view to developing a stability-indicating assay method. Initially, Chloroform: methanol (5:5v/v) gave good resolution but high Rf value of 0.95 for Valganciclovir hydrochloride, to reduce the Rf value then the mobile phase was optimized to Chloroform: Methanol: Ammonia (6.5:3.4:0.1v/v) Finally, the mobile phase consisting of gave a sharp and well-defined peak at $\mathrm{Rf}$ value of 0.74 . The spots were obtained when the chamber was saturated with the mobile phase for 15 min at room temperature.

\subsection{Calibration curve}

The linear regression data for the calibration curves showed a good linear relationship over the concentration range 100-500ng/band. The results were depicted in (table 1).3D view (Fig.2) Linear regression equation was found to be $Y=10.168 x+94.8$ and $R^{2}=0.9993$. The calibration curve was shown in the (Fig.3).

\begin{tabular}{lll} 
& Table 1: Linearity & \\
\hline SI.NO & CONCENTRATION & PEAK AREA \\
\hline 1 & 100ng/spot & 2143 \\
2 & 200ng/spot & 3169 \\
3 & 300ng/spot & 4213 \\
4 & $400 \mathrm{ng} / \mathrm{spot}$ & 5125 \\
\hline
\end{tabular}

*Mean of six estimations.

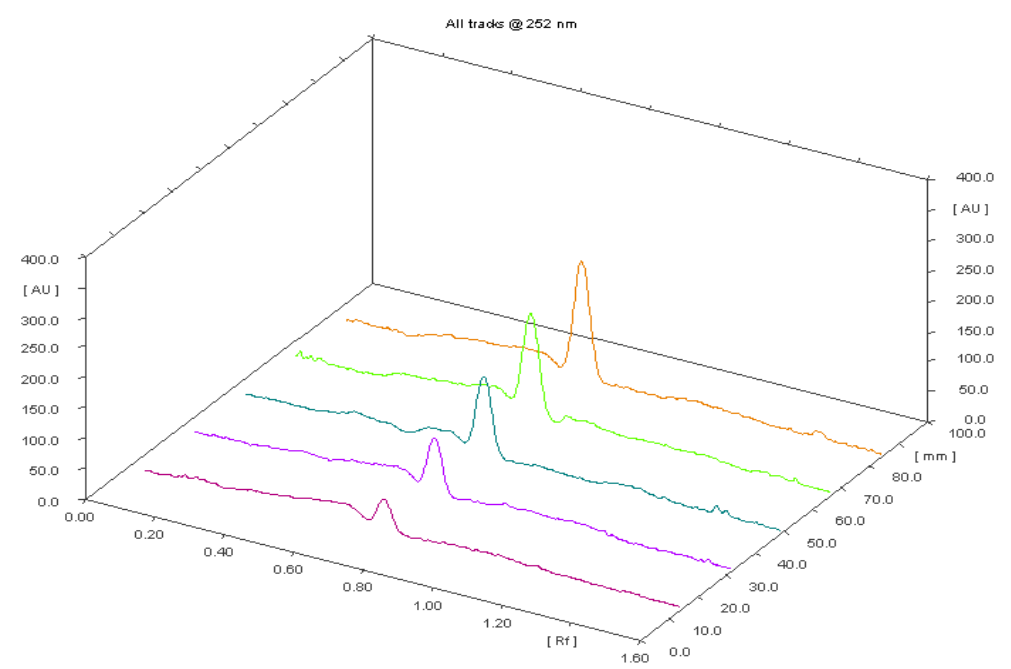

Fig. 2: 3D-Chromatogram Show Peaks of Valganciclovir in Different Concentrations at $254 \mathrm{Nm}$. 


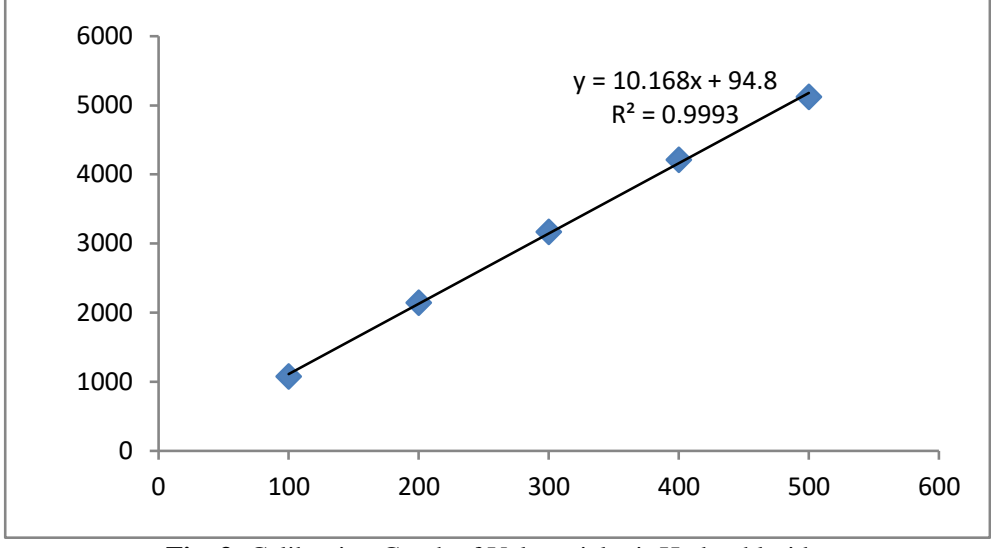

Fig. 3: Calibration Graph of Valganciclovir Hydrochloride.

\subsection{Validation of the method}

The summary of validation parameters is shown in the (Table 2).

Table 2: Summary of Validation Parameters

\begin{tabular}{lll}
\hline S.NO & PARAMETER & RESULTS \\
\hline 1 & Linearity & $100-500 \mathrm{ng} / \mathrm{spot}$ \\
2 & Regression equation & Y=10.168x +9 94.8 \\
3 & Slope & 10.168 \\
4 & Intercept & 94.8 \\
5 & Correlation coefficient $\left(\mathrm{R}^{2}\right)$ & $\mathrm{R}^{2}=0.9993$ \\
6 & Limit of detection & 9.19 \\
7 & Limit of quantification & 27.87 \\
8 & Specificity & Specific \\
9 & Recovery $(\mathrm{n}=6)$ & 99.66 \\
\hline
\end{tabular}

\subsection{Precision}

The precision of the above method was expressed in terms of \%relative standard deviation (\% RSD). The results depicted in (Table 3 ).

Table 3: Precision

\begin{tabular}{|c|c|c|c|c|}
\hline & INTRA-DAY STUDIES & & INTER-DAY STUDIES & \\
\hline SI.NO & Concentration (ng / spot) & AREA & Concentration (ng/spot) & AREA \\
\hline 1 & 400 & 4213 & 400 & 4213 \\
\hline 2 & 400 & 4089 & 400 & 4139 \\
\hline 3 & 400 & 4156 & 400 & 4259 \\
\hline 4 & 400 & 4156 & 400 & 4332 \\
\hline 5 & 400 & 4243 & 400 & 4246 \\
\hline 6 & 400 & 4223 & 400 & 4254 \\
\hline AVG & & 4180 & AVG & 4240.5 \\
\hline STDEV & & 57.1664 & STDEV & 63.2226 \\
\hline$\%$ RSD & & $1.37 \%$ & $\%$ RSD & $1.49 \%$ \\
\hline
\end{tabular}

\subsection{LOD and LOQ}

Detection limit and quantification limit was calculated by the method described above. The LOQ and LOD were found to be 9.19 and 27.87 respectively. This indicated adequate sensitivity of the method.

\subsection{Specificity}

The peak purity of Valganciclovir Hydrochloride was assessed by comparing the spectra at peak start, peak apex and peak end positions of the spot, i.e., $r(\mathrm{~S}, \mathrm{M})=0.999$ and $\mathrm{r}(\mathrm{M}, \mathrm{E})=0.999$. Good correlation $\left(\mathrm{r}^{2}=0.9993\right)$ was also obtained between standard and sample spectra of Valganciclovir Hydrochloride.

\subsection{Ruggedness}

When the method was performed by two different analysts under the same experimental and environmental conditions, it was found to be rugged (Table 4).

Table 4: Ruggedness

\begin{tabular}{lll}
\multicolumn{2}{c}{ Table 4: Ruggedness } \\
\hline Analysts & $\begin{array}{l}\text { Mean area* } \pm \text { Standard } \\
\text { deviation }\end{array}$ & $\%$ RSD \\
\hline Analyst 1 & $4217 \pm 64.264$ & $1.52 \%$ \\
Analyst 2 & $4223 \pm 36.9143$ & $0.87 \%$ \\
\hline
\end{tabular}

*indicates average of six determinations.

\subsection{Recovery study}


The proposed method when used for extraction and estimation of Valganciclovir Hydrochloride from the pharmaceutical dosage form after overspotting with 50,100 and $150 \%$ of additional drug, affording good recovery of Valganciclovir Hydrochloride. The \% recovery is listed in (Table 5).

Table 5: Recovery Studies

\begin{tabular}{|c|c|c|c|c|c|c|}
\hline Tablet & $\begin{array}{l}\text { Spiked lev- } \\
\text { els }\end{array}$ & $\begin{array}{l}\text { Amount of sample } \\
\text { (ng/spot) }\end{array}$ & $\begin{array}{l}\text { Amount of standard } \\
\text { (ng/spot) }\end{array}$ & $\begin{array}{l}\text { Amount recov- } \\
\text { ered }\end{array}$ & $\%$ Recovery $\pm \mathrm{SD}^{* *}$ & $\%$ RSD \\
\hline \multirow{3}{*}{$\begin{array}{l}\text { VALCYTE } \\
450 \mathrm{mg}\end{array}$} & 50 & 300 & 150 & 447.02 & $99.66 \pm 1.035$ & 1.03 \\
\hline & 100 & 300 & 300 & 597.07 & $99.51 \pm 0.32$ & 0.335 \\
\hline & 150 & 300 & 450 & 752.39 & $99.74 \pm 0.74$ & 0.75 \\
\hline
\end{tabular}

\subsection{Robustness of the method}

The standard deviation of peak areas was calculated for each parameter, and the \%RSD was found to be less than $2 \%$ The low values of $\%$ RSD (Table 6) indicated that the method was robust.

Table 6: Results of Robustness for Valganciclovir Hydrochloride

\begin{tabular}{ll}
\hline Parameters & $\%$ RSD \\
\hline Mobile phase volume $( \pm 2 \mathrm{ml})$ & 1.52 \\
Development distance $( \pm 0.5 \mathrm{~cm})$ & 1.80 \\
Duration of saturation $( \pm 10 \mathrm{~min})$ & 0.76 \\
Time from spotting to chromatography $( \pm 10 \mathrm{~min})$ & 0.33 \\
Time from chromatography to Scanning $( \pm 10 \mathrm{~min})$ & 0.12 \\
\hline
\end{tabular}

*Mean of three estimations.

\subsection{Analysis of the marketed formulation}

A single spot at Rf 0.49 was observed in the chromatogram of the drug samples extracted from the tablets. There was no interference from the excipients. The \%drug content and \%RSD were calculated. The low \% RSD value indicated the suitability of this method for the routine analysis of Valganciclovir Hydrochloride in pharmaceutical dosage forms (Fig. 5).

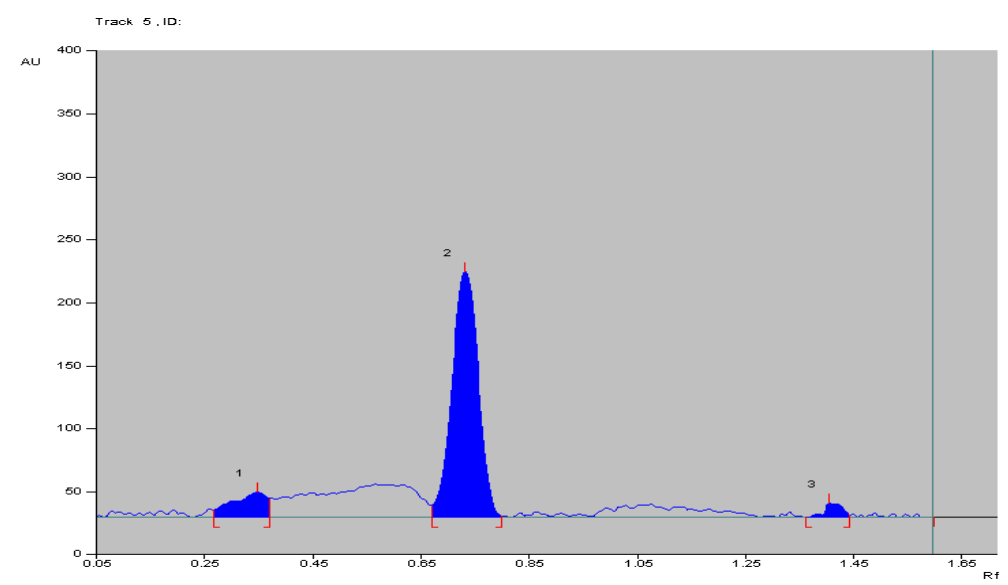

Fig. 5: HPTLC Chromatogram of Valganciclovir (TABLET) with Corresponding Rf Value at $254 \mathrm{Nm}$.

\section{Conclusion}

This HPTLC method is simple, precise, specific and accurate. Statistical analysis proved that the method is reproducible and selective for the analysis of Valganciclovir Hydrochloride as the bulk drug and in tablet formulations

\section{Acknowledgment}

We like thanks to Management, Principal, Teaching staff, non-teaching staff and my dear Friends of Bharathi College of pharmacy for their continues co-operation and support.

\section{Abbreviations}

HPTLC: High performance thin layer chromatography.

ICH: International council for Harmonization.

LOD: Limit of detection.

LOQ: Limit of quantitation.

RSD: Relative standard deviation.

\section{References}

[1] https://www.drugfuture.com/Pharmacopoeia/USP32/pub/data/v32270/usp32nf27s0_m87581.html 
[2] https://www.drugbank.ca/drugs/ Valganciclovir hydrochloride.

[3] https://www.webmd.com/drugs/2/drug-20977/ Valganciclovir-oral/details

[4] Porter SR, Kaplan JL. Merck index manual of diagnosis and therapy. 19th ed. Merck sharp \& Dohme corp: New Jersey; 2011.

[5] O'Neil JM, Heckelman EP, Dobbelaar HP, Roman JK, Kenny MC, Karaffa SL. The merck index an encyclopedia of chemicals, drugs and biological, 15thed. Royal society of chemistry: United Kingdom; 2013.

[6] U.S Pharmacopoeia-National Formulary [USP 34 NF 29]. Vol III. Baltimore. Rockville Md: United States pharmacopoeial convention, united book press; 2011.

[7] Kar A. Pharmaceutical drug analysis. 2thed. New age international private limited: New Delhi; 2005.

[8] Sharma BK. Instrumental method of chemical analysis. 23rded. Goel publishing house: Meerut; 2004.

[9] Willard HH, Merritt LL, Dean JJA, Frank AS. Instrumental method of analysis: 23rded. CBS publishers and Distributers: New Delhi; 1986.

[10] Schartz ME, Krull IS. Analytical method development and Validation: 1sted. CRC press: US; May 1997.

[11] Dasari V, Chandu BR, Khagga M, Gindi S. New simple UV spectrophotometric method for the estimation of Valganciclovir in bulk and its formulation. Int J Adv Pharm sci 2010;1(2):282-6.

[12] Mondal S, Reddy GS, Mondal P, Prathyusha VS, Nair AP, Rahaman ST. Development and Validation of Few UV Spectrophotometric Methods for the Determination of Valganciclovir in Bulk and Pharmaceutical Dosage Form. J Pharm Anal Pharm 2018;9(2):64-8. https://doi.org/10.5530/phm.2018.2.12.

[13] Awen BZ, Dassari V, Chandu BR, Khagga M, Katakam P. New simple UV Spectrophotometric method for the estimation of Valganciclovir in bulk and its formulation. Int J Pharm Res 2011;2(1):55-8.

[14] Krishna Veni N, Gowramma B, Madhuri L, Gouthami B, Sindhur Nag N, Meyyanathan SN. Development and Validation of a Stability Indicating RP-HPLC Method for the Determination of Valganciclovir Hydrochloride (RS). J Pharm Anal 2014;3(1):19-26.

[15] Ramesh G, Subba Rao M. Development and Validation of Stability Indicating RP-HPLC Method for Quantitative Determination of Valganciclovir in Pure and Pharmaceutical Formulations. Int J Pharm Res 2015;3(1):1-14.

[16] Sawant S, Barge V. A Validated Stability Indicating RP-HPLC Method for Valganciclovir, Identification and Characterization of forced Degradation Products of Valganciclovir Using LC-MS/MS. Acta Chromatographica 2014;29(1):29-42. https://doi.org/10.1556/AChrom.26.2014.1.4.

[17] Mondal S, Reddy GS, Mondal P, Prathyusha VS, Nair AP, Rahaman ST. A New Stability Indicating Ultra Performance Liquid ChromatographyPDA Method for the Estimation of Valganciclovir in Bulk and Tablet Dosage Form. J Pharm Anal Pharm 2018;9(2):94-8. https://doi.org/10.5530/phm.2018.2.16.

[18] Surekha ML, Swamy GK. High performance thin layer chromatographic method for determination of Valgacyclovir in tablet dosage form. Bull Pharm Med Sci 2013;1(1):44-8.

[19] Annapurna MM, Tulasi KL, Sirichandra M. Stability indicating Liquid chromatographic method for the quantitative determination of Valganciclovir in pharmaceutical dosage forms J Drug Deliv Ther. 2013;3(3):64-70. https://doi.org/10.22270/jddt.v3i3.498.

[20] Malleswara Rao SN, Srinivas K, Suryanarayana MV, Madhavan P, Mukkanti K. A Validated LC Method for the Determination of Chiral Purity of (S)-2-azido3-methylbutanoic acid: A key Raw material of Valganciclovir hydrochloride. J Chem Pharm Res 2011;3(4):22-28

[21] Sura S, Modalavalasa RR, Chandra Sekhar KB. Development and Validation of Stability Indicating RP-Liquid Chromatographic Method for the Quantitative Determination of Valganciclovir. Der Pharma Chemica 2017;9(19):101-109.

[22] ICH, Q2 (R1) Validation of Analytical Procedures: text and methodology. European medicine agency: United Kingdom; June 1995. 